\title{
Cisto Pilonidal Sacrococcígeo: Resultados do Tratamento Cirúrgico com Incisão e Curetagem
}

\author{
Pilonidal Sinus: Surgical Treatment Results with Incision and Curettage
}

\author{
FLÁVIABALSAMO ${ }^{1}$;ALLINE MACIELPINHEIRO BORGES²; GALDINO JOSÉ SITONIOFORMIGA ${ }^{3}$ \\ ${ }^{1}$ Assistente do Serviço de Coloproctologia do Hospital Heliópolis, São Paulo- S.P., TSBCP; ${ }^{2}$ Ex-residente do Serviço de \\ Coloproctologia do Hospital Heliópolis, São Paulo-S.P, FSBCP; ${ }^{3}$ Chefe do Serviço de Coloproctologia do Hospital \\ Heliópolis, São Paulo- S.P., TSBCP.
}

\begin{abstract}
BALSAMO F; BORGES AMP; FORMIGA GJS. Cisto Pilonidal Sacrococcígeo: Resultados do Tratamento Cirúrgico com Incisão e Curetagem. Rev bras Coloproct, 2009;29(3): 325-328.

RESUMO: duzentos e treze doentes com cisto pilonidal sacrococcígeo foram submetidos a tratamento cirúrgico pela técnica de incisão e curetagem, no período de janeiro de 1997 a dezembro de 2006. Foram avaliados o sexo, a idade o tipo de anestesia, o tempo de internação, período de cicatrização, complicações e seguimento. Conclui-se que a técnica de incisão e curetagem é uma boa opção no tratamento cirúrgico do cisto pilonidal sacrococcígeo, proporcionando tempo aceitável de cicatrização e baixos índices de recidiva.
\end{abstract}

Descritores: Cisto pilonidal, Curetagem, Anestesia local, Tratamento, Cicatrização.

\section{INTRODUÇÃO}

O cisto pilonidal consiste em processo inflamatório crônico que ocorre com bastante frequência na região sacrococcígea, estando geralmente associado à presença de pêlos. É mais comum em homens do que mulheres na razão de $3: 1$, principalmente no início da terceira década de vida ${ }^{1,2}$.

Esta doença foi inicialmente descrita por Mayo, $1833^{3-5}$ e Anderson, em $1847^{6,7}$. Os métodos empregados para seu tratamento eram baseados em estudos embriológicos ${ }^{5}$ e que explicavam a doença com base em origem congênita. Foram postuladas diversas teorias dentro deste âmbito como a presença de vestígios do canal medular, tração ou inclusão dermóides e a presença dos vestígios glandulares ${ }^{7}$. Tais teorias justificariam a exérese completa destes remanescentes embriológicos $5,8,9$.

Em 1946, Patey e Scarff levantaram a possibilidade de uma forma adquirida da enfermidade, a qual atingiu popularidade, após sucessivas investi- gações clínicas e histopatológicas ${ }^{4,8,10}$. Estes autores demonstraram a ausência de folículos pilosos no cisto $^{3}$ e a reação granulomatosa de corpo estranho $7,11,12$. Surgiram diversas abordagens cirúrgicas e dentre estas a técnica da incisão e curetagem que, pela simplicidade de execução e pela pouca excisão tecidual, adequou-se a esta proposição, favorecendo também a utilização da anestesia local associada e sedação ${ }^{4,7,12}$.

O objetivo deste trabalho é descrever a experiência com o tratamento cirúrgico do cisto pilonidal sacrococcígeo, no Serviço de Coloproctologia do Hospital Heliópolis - SP, utilizando-se a técnica de incisão e curetagem em período de dez anos.

\section{PACIENTES E MÉTODOS}

Foi realizado estudo retrospectivo, no período de janeiro de 1997 a dezembro de 2006, com portadores de cisto pilonidal sacrococcígeo não complicado tratados pela técnica de incisão e curetagem. 
Não foram incluídos no estudo crianças ou pacientes com cisto pilonidal recidivados. Foram resgatados dados tanto de prontuários de internação como de seguimento ambulatorial.

Os pacientes foram submetidos a exame físico geral e local minuciosos, com finalidade de registrar a extensão da lesão, localização dos orifícios fistulosos, e o perfil psicológico de cada paciente. Tais cuidados permitiram identificar aqueles com perfil psicológico suscetível à realização do tratamento cirúrgico com anestesia local ou bloqueio.

A sedação, quando associada a anestesia local, foi realizada com Midazolan, administrado por via endovenosa na dosagem de $0,1 \mathrm{mg} / \mathrm{Kg}$, com finalidade principal de produzir amnésia no início da infiltração, momento de maior dor. O tipo de infiltração anestésica foi em forma de "leque" em torno da lesão, utilizandose inicialmente dois pontos de infiltração laterais e, posteriormente, na extremidade proximal e distal da lesão, formando assim um losango de área anestesiada em torno da mesma. Os anestésicos locais utilizados foram a Lidocaína $2 \%$ e Bupivacaína $0,5 \%$ sem vasoconstritor, com o cuidado de não ultrapassar a dosagem de segurança de cada droga. Tal procedimento foi acompanhado de monitorização cardiológica e oximetria por membro da equipe cirúrgica ou da equipe de anestesia. Nos casos onde escolhemos o bloqueio, deixamos ao encargo da equipe de anestesia a escolha das drogas a serem utilizadas.

Todos os pacientes foram submetidos ao procedimento de incisão e curetagem, técnica em que os orifícios fistulosos são cateterizados com estilete, iniciando-se pelo orifício primário da lesão em direção aos secundários, com posterior incisão dos trajetos, regularização dos bordos, curetagem do tecido de granulação, hemostasia com eletrocautério e curativo habitado em área cruenta.

Os dados referentes a idade, sexo, raça, tipo de anestesia, tempo de internação, período de cicatrização, complicações e seguimento foram submetidos a análise estatística, tendo a estatística descritiva sido contemplada com a apresentação de gráficos e tabelas de frequências absolutas e relativas (\%). A análise dos dados foi obtida pelo teste de t de Student, para variáveis contínuas e teste não paramétrico do qui-quadrado para variáveis nominais.

Em todas as situações analíticas foi utilizado o limite de $5 \%(\mathrm{p}<0,05)$ para afirmativa de diferença estatisticamente significante. Foi utilizado o software SPSS 13.0 (Chicago-USA) para as análises.

\section{RESULTADOS}

Foram estudados 213 doentes operados de cisto pilonidal sacrococcígeo não complicado pela técnica de incisão e curetagem no período de janeiro de 1997 a dezembro de 2006.

A idade dos doentes variou de 13 a 74 anos, sendo que $172(80,7 \%)$ tinham idade entre 13 e 30 anos. (Figura 1) Quanto ao sexo, $136(63,8 \%)$ pertenciam ao masculino e $77(36,2 \%)$ ao feminino. (Figura 2)

A raça branca predominou em 210 doentes $(98,6 \%)$, havendo três doentes da raça negra $(1,4 \%)$. (Figura 3)

A anestesia preferida foi a local em 169 pacientes, tendo sido exclusiva em $76(35,7 \%)$ e associada

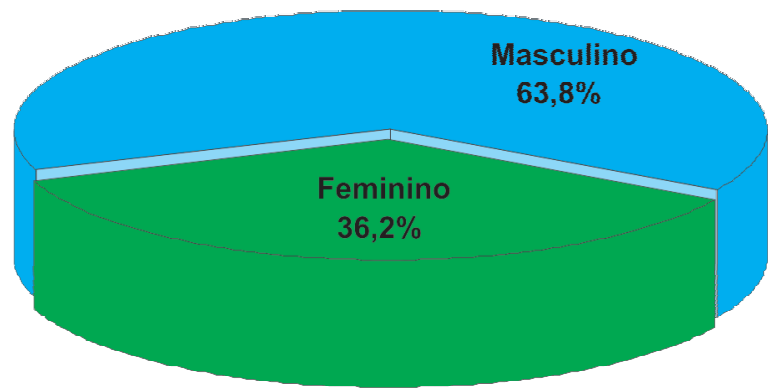

Figura 1 - Distribuição por sexo.

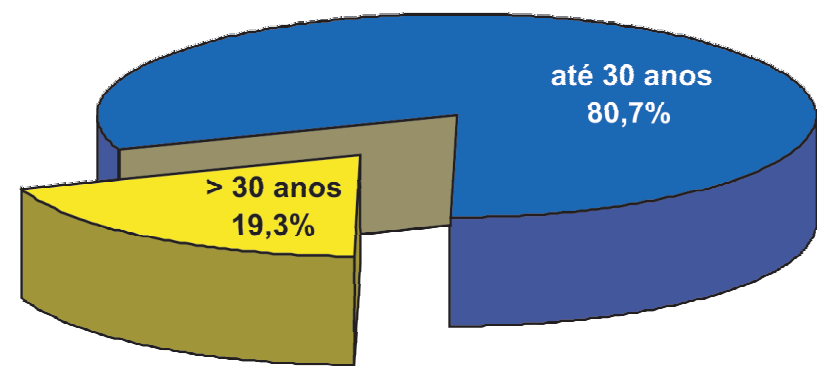

Figura 2 - Distribuição por idade.

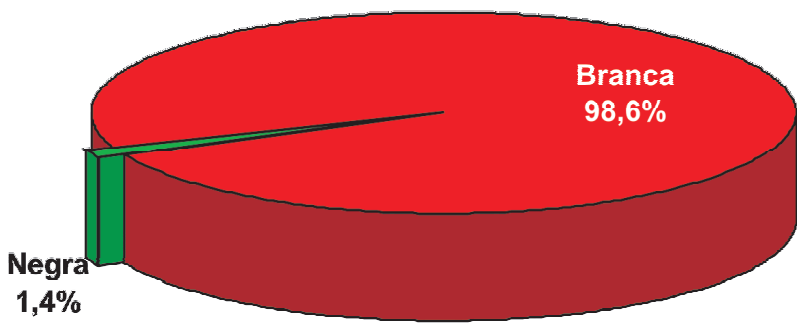

Figura 3 - Raça. 
à sedação em $93(43,7 \%)$. O bloqueio raquimedular foi realizado em 44 doentes $(20,6 \%)$. (Figura 4$)$

A droga Midazolan, utilizada para sedação em associação à anestesia local provocou certo grau de amnésia nos pacientes em relação ao ato operatório e, principalmente, no momento da infiltração anestésica local. O efeito anestésico teve início em menos de dois minutos e prolongou-se por duas horas.

Não houve complicações anestésicas neste grupo estudado. Houve cinco casos $(2,2 \%)$ de sangramento no pós-operatório imediato tratados conservadoramente com curativos compressivos e/ ou pequenos pontos hemostáticos com fio absorvível.

Todos os doentes receberam alta hospitalar no primeiro dia de pós-operatório, assintomáticos. A dor no pós-operatório foi controlada com dipirona e antiinflamatórios não esteroidais.

O tempo de cicatrização foi em média 52 dias, variando de 20 a 200 dias. Os casos com maior demora no tempo de cicatrização foram aqueles com cistos mencionados como sendo grandes, entretanto não foram mensurados. (Tabela 1 )

As recidivas ocorreram em cinco pacientes $(2,3 \%)$. Três eram portadores de cistos grandes e o procedimento de incisão e curetagem foi repetido com

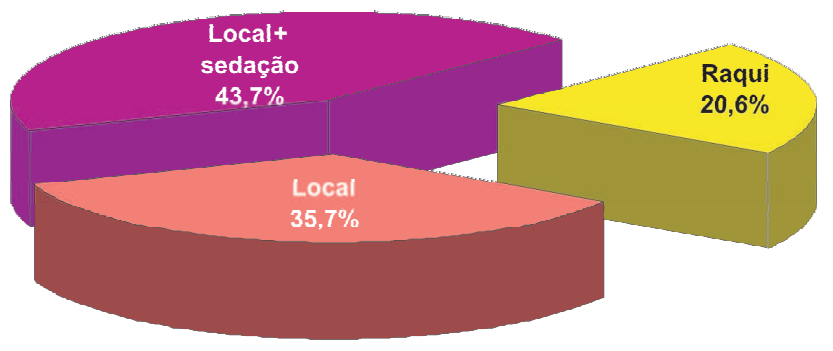

Figura 4 - Tipo de anestesia. sucesso em quatro pacientes. Em um paciente houve necessidade de quatro intervenções, com persistência da recidiva e posterior perda do seguimento ambulatorial. O tempo médio de seguimento foi de seis meses.

\section{DISCUSSÃO}

A origem do cisto pilonidal sacrococcígeo sempre foi motivo de interesse, estudos e controvérsias em nosso meio. Por se tratar de doença com maior incidência em brancos, sexo masculino e jovens, principalmente abaixo dos 25 anos, ${ }^{2}$ foi alvo de pesquisas com finalidade de desvendar sua verdadeira etiologia e vislumbrar um tratamento próximo do ideal: indolor, sem recidiva e com resultados estéticos satisfatórios ${ }^{5}$.

A progressiva aceitação da teoria adquirida ${ }^{4}$ gerou o aparecimento de diversas modalidades cirúrgicas no tratamento do cisto pilonidal, porém com características diferentes quanto ao modelo ideal. Dentre estas, a incisão e curetagem que, por sua simples execução e pouca excisão tecidual parece preencher boa parte de tais quesitos ${ }^{7}$.

Tal técnica adapta-se tanto ao tratamento eletivo da doença como na doença abscedada, podendo ser utilizada inclusive em nível ambulatorial, já que em boa parte dos casos permite a utilização da anestesia local, o que também foi possível identificar nesta amostra.

A baixa morbidade com rápida recuperação, baixo índice de complicações e alta hospitalar precoce também constituem pontos favoráveis à execução da técnica, o que permite retorno precoce às atividades. Foi possível constatar o mesmo achado nesta amostra, com sangramento no pós-operatório imediato em ape-

Tabela 1 - Distribuição das frequências absolutas (n) e relativas (\%) das variáveis do estudo (Hospital Heliópolis 1997-2006).

\begin{tabular}{llcc}
\hline Variáveis & Categorias & Frequência n (\%) \\
\hline Tempo de cicatrização (dias) & Média & $52(+/-24)$ \\
& Amplitude & $20-200$ \\
Anestesia & Local & 76 & $(37,5)$ \\
& Local + sedação & 93 & $(43,7)$ \\
\multirow{3}{*}{ Recidiva } & Raqui & 44 & $(20,6)$ \\
& Sim & 5 & $(2,3)$ \\
& Não & 208 & $(97,7)$ \\
\hline
\end{tabular}


Rev bras Coloproct Julho/Setembro, 2009 nas $2,2 \%$, tratados conservadoramente e recidiva em somente $2,3 \%$ dos casos ${ }^{9,12}$.

O tempo de cicatrização para a incisão e curetagem, técnica baseada na cicatrização por segunda intenção, foi de 52 dias (+/- 24 dias) e parece estar na média para a técnica em questão, que é de oito semanas, como relatado em outros estudos ${ }^{4}$. Tal período somente foi mais prolongado nos pacientes com cistos grandes ou em pacientes com dificuldade no asseio local. A taxa de recidiva de $2,3 \%$, considerada baixa, também foi a relatada pela literatura consultada.
O seguimento de seis meses ainda é curto, porém o de longo prazo, neste tipo de afecção benigna é de difícil realização, já que há pouco interesse dos pacientes em retornar para acompanhamento, mesmo quando solicitados.

\section{CONCLUSÃO}

A técnica de incisão e curetagem além de fácil execução é uma boa opção no tratamento cirúrgico do cisto pilonidal sacrococcígeo promovendo tempo razoável de cicatrização, alta precoce e baixo índice de recidiva.

\footnotetext{
ABSTRACT: From January 1997 to December 2006, 213 patients with pilonidal sinus have undergone on surgical treatment with incision and curettage technique. We analyzed age, sex, the anesthetic and surgical procedures, recovery as well as healing time and follow up. We have concluded that incision and curettage in surgical treatment of pilonidal sinus is a good option, with quick recovery and an acceptable healing time.
}

Key words: Pilonidal sinus, Curettage, Local anesthetic, Treatment, Healing.

\section{REFERÊNCIAS}

1. Billingham RP. Pilonidal disease, anal cancer, Bowen's and Paget's diseases, foreign bodies and hidradenitis suppurativa. Anorrectal Miscellany, 1999;26:171-7.

2. Blake PP, Bardavid CS, Guzman HC, Rodriguez LG, Albarran VR, Alamo MA, et al. Tratamiento quirúrgico del quiste pilonidal. Rev Chil Cir, 1997;49:692-7.

3. Karydakis GE. Easy and successful treatment of pilonidal sinus alter explanation of its causative process. Aust NZJ Surg, 1992;62:385-9.

4. Ramos AC, Galvão MPN, Cecconello I, Zilberstein B. Tratamento do cisto pilonidal utilizando eletrocauterização. Rev bras Coloproct, 1998;11:5-8.

5. Hull TL, Wu J. Pilonidal disease. Surg Clin N Am, 2002;82:1169-85.

6. Goligher JC - Cirurgia del ano, recto y colon. $2^{\mathrm{a}}$. ed., Salvatti,1987.

7. Silva JH - Cisto pilonidal sacrococcígeo. Contribuição ao tratamento cirúrgico pela técnica de incisão e curetagem. São Paulo, 1972. (Tese de doutoramento da Faculdade de Medicina da Universidade de São Paulo).
8. Roldos LEV, Aragón ER. Tratamiento quirurgico ambulatorio de la enfermedad pilonidal. Rev Cubana Cir, 1990;29:309-13.

9. Nahas SC, Sobrado CW, Araujo SEA, Imperiale AC, HabrGama A, Pinotti HW. Resultados do tratamento cirúrgico de cisto pilonidal não complicado. Rev Hosp Clin Med S Paulo, 1997;52:287-90.

10. Akinci OF, Bozer M, Uzunkoy A, Duzgun SA, Cuskun A. Incidence and aetiological factors in pilonidal sinus among turkish soldiers. Eur J Surg, 1999;165:339-42.

11. Bascom JU. Cirurgia pilonidal: como adequar o tratamento à enfermidade. Rev bras Coloproct, 1996;6:89-94.

12. Rossoni MD, Albino PA, Nunes BLBBP, Abud RM, Formiga GJS, Silva JH. Cisto pilonidal fistulizado de margem analrelato de dois casos. Rev bras Coloproct, 1997; 17 :251-3.

\author{
Endereço para correspondência: \\ FLÁVIA BALSAMO \\ Serviço de Coloproctologia do Hospital Heliópolis \\ R. Cônego Xavier, 276- Vila Heliópolis \\ 04231-030- São Paulo, SP \\ Tel.: (11) 2274-7600 (ramal 244) \\ Fax: 11-2247-7646 \\ E-mail: flabal@uol.com.br
}

